\title{
MAJOR POWER INTERSTATE CONFLICT IN THE POST-WORLD WAR II ERA: AN INCREASE, A DECREASE, OR NO CHANGE?
}

\author{
Richard J. STOLL \\ Rice University
}

$\mathrm{T}$

HE SECOND World War is often regarded as a watershed in world history. Observers have pointed to a number of changes in the global system that occurred after its conclusion: the emergence of bipolar system structure, along with new contenders for international leadership; the invention (and subsequent proliferation) of weapons of extreme power; and the explosion of new nation-states that has created a truly global system. But have these changes been accompanied by changes in behavior between nation states? This paper will investigate one aspect of interstate behaviormilitary conflict involving the major powers-and ascertain whether the time period 1946-1976 was marked by a sharp change in the amount of this conflict, as compared to the period 1816-1945.

\section{Why Change Might Be Expected}

Each of the three changes noted above has led to assertions about the amount of conflict in the post-World War II era. Although there is general agreement on the nature of these changes, scholars and practitioners have differed in their conclusions as to the strength and direction of their association with the amount of conflict. Let us briefly consider the three sets of assertions about change and conflict under the headings of system polarity, the political utility of force, and the growth in the size of the interstate system.

\section{Polarity}

The first set of assertions begins with a consideration of the polarity of the interstate system in the post-World War II era. Most observers start from the premise that this time period, unlike the century-and-a-half preceding it, has been bipolar, at least until the late 1960s (Deutsch and Singer, 1964; Waltz, 1967; Rosecrance, 1966; but see Bueno de Mesquita, 1975). This dramatic change in system structure is thought to lead to an equally dramatic change in the amount of conflict. Since my concern here is not to test the polarity argument per se, I will bypass most of the disagreements in this literature ${ }^{1}$ and merely indicate the differences in predictions of expected amount of conflict in a bipolar system. All would agree that the more bipolar a system is,

NOTE: The data used in this paper were kindly made available to me by the Correlates of War Project at the University of Michigan under the direction of J. David Singer and Melvin Small. I would also like to acknowledge the aid of Patty Renfrow in conducting the analyses. Responsibility for all errors is mine.

${ }^{1}$ For example, is polarity (a) a function of the bonding patterns of nations; (b) a function of the distribution of power across nations; or (c) a function of both? The system structure "debate" has its origins in arguments about whether a balance of power system existed in Europe and whether it preserved peace and/or stability. 
the easier it is to tell "friend" from "foe" and make calculations as to how nation states will line up in any confrontation. The disagreement concerns whether this high level of certainty (as compared to a multipolar system) is conducive to peace. Bipolarity advocates believe that wars are more likely to occur through miscalculation and that miscalculation is more probable under low levels of certainty (i.e., with a multipolar system). Multipolarity advocates, on the other hand, believe that wars are more likely to occur through deliberate, calculated choice. They argue that the clarity of a bipolar system structure leads to high levels of certainty by decision-makers. This in turn means that a cost-benefit calculation favorable toward war is more likely to occur with a bipolar system. Under conditions of uncertainty, as would be present with multipolarity, decision-makers are more likely to be cautious and restrain themselves from war.

\section{The Political Utility of Military Force}

The second set of assertions concerns the political utility of military force in the post-World War II era. For reasons discussed below, some observers believe that the utility has decreased, and therefore, since governments are not completely irrational, the use of force is (and should be) on the wane. Other observers are more skeptical and believe that the utility of force has not been reduced; hence, its use should not have decreased (Halle, 1973, is optimistic; Art, 1980, is not). The arguments on this subject will be presented from the point of view of those who believe that military conflict is (and will) occur less frequently.

The first element in these arguments is that the use of military force is increasingly regarded as being undesirable; in fact, more and more people see it as illegal. Obviously, there is no enforceable code of conduct for governments, but to the extent that "self-help" (i.e., the resort by government to use of force) is seen as an unacceptable doctrine, one would expect to see it used less frequently. Lending support to the first part of this argument is a recent study examining over 200 legal treatises from 1815 to 1974 (Kegley, Raymond, and Choi, 1979). The results indicate that references to war shifted from assertions that it was a permissible action toward the position that it was not a legal act. ${ }^{2}$

The second element in arguments about the political utility of force is based on the increased potential cost of using force. In particular, it is noted that the outbreak of conflict poses the prospect of escalation to a massive thermonuclear exchange, with attendant massive destruction, if not annihilation, of one or more nation states. ${ }^{3}$ Given these potentially high costs,

${ }^{2}$ However, it is noted that the relationship between viewing war as an illegal act in legal treatises and actual nation state behavior, though negative (i.e., the more illegal it is regarded, the less the amount of war in the international system), is a weak one.

${ }^{3}$ Even for those who foresee a dramatic difference between victory and defeat in a thermonuclear exchange (for example, Gray and Payne, 1980) use a figure of 20 million casualties for the United States, and that is with what they regard as an "intelligent U.S. offensive strategy wedded to homeland defenses." This figure is roughly 33 percent higher than the battle deaths suffered by all belligerents in World War II and about 100 percent higher than the battle deaths suffered by all belligerents in World War I (Singer and Small, 1972: 66-67). 
governments will be reluctant to engage in the use of military force themselves and to restrain the use of force by other governments. The latter follows since the externalities of any conflict between nation states may involve costs to uninvolved governments.

The third element in the argument about the declining utility of force makes reference to the rise of interdependence between nation states (Keohane and Nye, 1977). Parts of the rising-interdependence rationale overlap with the previously stated arguments, but it also has some unique aspects. In particular, it is argued that as interdependence increases between nation states, a variety of mutually profitable relationships will be created and/or expanded between them. Use of force between nations will rupture these relationships. Since, under conditions of interdependence, military security no longer occupies the unquestioned primary position in governmental goal hierarchies, the breaking of these relationships will be viewed as very costly. These increasing costs also mean that military force cannot be used as an instrument of linkage to other issue areas. This further reduces the utility of force.

\section{The Increase in Nation States}

The final set of assertions connecting a characteristic of the post-World War II era with a change in amount of conflict is based on the observation that there are many more nation states in this most recent era than ever before. Between 1816 and 1939 the average number of nation states in the system was 40.5; from 1945 to 1977 , the average leaps to 110.4

Even if the propensity of any individual nation to become involved in conflict has not changed, the explosion in the number of nation states implies that there are many more opportunities for conflict to arise; therefore, the absolute amount of conflict in the international system should rise, even if the involvement by any particular nation state does not.

\section{A Necessary Digression}

At this point, let me raise an issue that has implications beyond that of indicator construction. It is the matter of controlling for the number of nation states in the system when calculating the amount of military conflict. Because the size of the system increases so dramatically in the century-and-a-half under consideration, there is a strong argument to "normalize" conflict measures by dividing them by some function of the number of nation states (e.g., by the number of states or number of dyads). This enables us to measure per nation state unit involvement in conflict. However, if there is a chance that a conflict could escalate all the way to massive destruction (either on the scale of the World Wars, or beyond), then we would be just as interested in conflict per time unit, i.e., in conflict per year without controlling (and in most cases deflating) by nation state unit. It should be stressed that controlling for the number of nation states is not a question of right or wrong

${ }^{4}$ These figures were calculated from Table 3 in Small and Singer, 1979. In regard to major powers (whose conflict experience is central to the analyses in this paper), however, the average number in the system each year drops from 6 in the time period 1816-1939 to 4.7 from 1946 to 1977. 
but of the particular research interests at hand. In this paper, analyses will be presented both with and without normalizing for the size of the system.

As this brief review has indicated, a number of reasons have been advanced as to why the amount of military conflict in the post-World War II era should differ from that in the 130 years preceding it. However, consensus on the direction of this change is lacking; all three possibilities (higher, lower, no change) have been mentioned. In the succeeding sections of this paper, I will operationalize military conflict and test whether there has been a change when examining all the major powers together, as well as their individual experiences.

\section{The Data Base}

For purposes of this study, "military conflict" will be operationalized in terms of two different types of behavior: serious disputes (hereafter termed "'disputes'), and wars. Both data sets were collected by the Correlates of War Project at the University of Michigan under the direction of J. David Singer and Melvin Small and cover the time period 1816-1976.

The dispute data set has been collected only recently and is unfamiliar to many researchers. The following is a brief description of the data set. As of this writing, a summary handbook describing it in great detail is being prepared (Gochman, forthcoming).$^{5}$ A dispute is a situation where military force is threatened or actually used between nation states. It thus represents a behavior somewhere on the continuum between peace and war, and, in the minds of governmental decision-makers, raises the possibility of war as an outcome.

The presence of a dispute is inferred from the observation of one or more military force confrontations, hereafter termed "incidents." These are the individual threats and uses of force. In all, twelve types of incidents are coded in the data set. These incidents consist of three general types of military activity short of war: verbal threats of force (implying future action), displays of force (use of armed forces to demonstrate capacity, but not in military operations) and uses of force (use of armed forces in limited military operations). Each serious dispute in the data set consists of one or more of these incidents. Incidents are grouped together if they are seen as being part of the same historical episode in the appropriate monograph or specialized diplomatic or military history. However, if two incidents are separated in time by six months or more, they are automatically grouped into separate disputes. The process of aggregating incidents into disputes is far from a mechanical activity, requiring the use of judgment by both the coder and the source historian. But after five years of effort by the Project, they have high confidence in the grouping decisions that have been made.

Disputes can have one of two outcomes: war or no war. War is defined as continuous reciprocated military combat between organized units of the

\footnotetext{
${ }^{5}$ This summary covers only disputes involving at least one major power. Efforts are currently underway to extend the dataset to include minor power-minor power disputes. This is likely to result in a few changes to the major power interstate dispute collection but not a sufficient number to change the results of these analyses.
} 
armed forces of both sides, and operationalized by the measure of 1000 or more total battle deaths suffered by the participant nation states. ${ }^{6}$

Using these two basic variables, I constructed a number of indicators measuring the aggregate amount of conflict over time involving major powers. Analogous measures were also constructed for each individual major power's conflict involvement. The most basic indicators of conflict were simply the number of disputes per year and the number of wars per year. A third indicator used was the proportion of disputes escalating to war each year (note: if there were no disputes in a year, this variable was coded as missing). Separate indicators were also constructed to normalize the amounts of conflict for the growing number of nations in the system.

At the aggregate (i.e., major power-interstate) level, I distinguish between three categories of participation in conflict: conflicts involving major powers on both sides, conflicts involving major powers on only one side, and the summation of the two. The normalization used was to divide the frequencies per year by the appropriate number of dyads of nations. For the three categories of participation noted above, the normalizations are the number of major power-major power dyads, the number of major power-minor power dyads, and the sum of the two. Thus, in measuring the total amount of conflict over time, I have three classifications of participants, and within each of these classifications five measures of conflict per year (disputes, disputes per dyad, wars, wars per dyad, and wars per dispute).

Five similar conflict measures were also constructed for each individual major power's conflict involvement. Since the numbers of conflicts for each major power were smaller than for the aggregate, I did not construct separate indicators for each class of participant (i.e., French major power-minor power disputes per year). The normalization procedure for each individual major power was to divide disputes per year and wars per year by $\mathrm{N}-1$, where $\mathrm{N}$ equals the number of nations in the system. This figure represents the maximum number of conflict dyads a major power could participate in during that year. Finally, the conflict indicators were constructed only in those years that the nation state was a major power (i.e., individual indicators for the U.S. begin in 1899). Table 1 displays the nations that are considered major powers in the post-World II era and the dates of their membership in this elite club, as well as the year they acquired a nuclear weapons capability (see below). All other nation states in the system during a given year are considered to be minor powers.

\section{Examination of the Individual Major Powers}

The major powers constitute an oligarchy with many shared character-

\footnotetext{
${ }^{6}$ See Singer and Small, 1972. Note that the requirement for continuous combat between organized armed forces would seem to remove both the Hungarian Revolution and the Soviet invasion of Czechoslovakia from Soviet war involvements. In neither case is there evidence of much military coordination on the Hungarian or Czechoslovakian side. The Hungarian Revolution is included in Singer and Small's list of interstate wars; a figure of 25,000 is given for Hungarian battle deaths. Therefore, it is included in the analyses. To ensure that the Czech case in 1968 did not affect the results for the Soviet Union, all Soviet analyses were run both with and without a war coded as the outcome of the Russian-Czech dispute. Although this did not change the results markedly, both sets are reported when small differences occurred.
} 
TABle 1. Major Powers in the Study

\begin{tabular}{lcc}
\hline \hline Nation & Years Major Power & $\begin{array}{c}\text { Year Acquired } \\
\text { Nuclear Weapons Capability }\end{array}$ \\
\hline United States & $1899-1976$ & 1945 \\
United Kingdom & $1816-1976$ & 1952 \\
France & $1816-1940 ; 1945-1976$ & 1960 \\
Soviet Union & $1816-1917 ; 1922-1976$ & 1949 \\
China & $1950-1976$ & 1964 \\
\hline \hline
\end{tabular}

istics; they score far higher than the "average" nation state on measures of capability, conflict, and activity (Cusack, 1978: chapter 2). But in the postWorld War II era, we might expect some differences between them regarding conflict experiences. The post-World War II era witnessed the rise to superpower status of both the United States and the Soviet Union, along with the decline of Britain and France. China also achieved a broader recognition of its capabilities, but perhaps short of super-power status.

In keeping with their roles as superpowers and rivals, I would expect the United States and the Soviet Union to experience a rise in conflict activity in the post-World War II era; the same change would be expected for China. On the other hand, I would expect Britain and France to show a decline in conflict involvement, since their roles in the international system are smaller in the current (post-1945) era.

Most of the tests conducted in this paper divide the observations of conflict into two groups (e.g., pre- and post-World War II, pre- and postacquisition of nuclear weapons). The few explicit predictor variables will be discussed next in the section on hypotheses and methodology.

\section{Hypotheses and Methodology}

Three different techniques of analysis were used in this paper. Each tested a different variant of the basic research question: has there been a shift in the amount of military conflict in the post-World War II era? Further, three combinations of prediction-outcome variable sets were examined: the effect of aggregate major power interstate characteristics on aggregate major power interstate military conflict, the effect of these same aggregate characteristics on the conflict experience of each individual major power, and, finally, the effect of each individual major power's characteristics on its own military conflict level. These variable sets will be referred to as the aggregateaggregate, aggregate-individual, and individual-individual variable sets, respectively.

\section{Pre-test Post-test Differences: the T-test}

The first technique used is a simple t-test to ascertain whether the mean level of conflict changed after the introduction of an "experimental variable" (Campbell and Stanley, 1963). The hypothesis is that the introduction of this "variable" will lead to a change in the amount of conflict. At the aggregate- 
aggregate level, the experimental variable is occurrence of the post-World War II era. A total of 15 t-tests were run (there are five aggregate conflict measures for each of the three classes of conflict participants), with the pretest period being 1916-45 and the post-test period being 1946-76. ${ }^{7}$ The mean values for each of the five measures were computed before and after the 1946 breakpoint, and a t-test was used to determine if the post-World War II means were significantly different from the pre-World War II means.

Shifting to the aggregate-individual level, the experimental variable remains the same. But this time, the test is made on the conflict experience of each nation that was a major power both before and after World War II (see Table 1). The hypothesis tested is that the amount of conflict experienced by a major power will change in the post-World War II era. This set of analysis yielded a total of twenty t-tests (five conflict measures for each of the four nation states that were major powers both before and after World War II); once again, the t-test, is used to determine if the post-World War II mean differs from the pre-World War II mean on each indicator.

Finally, for the individual-individual analyses, the experimental variable was the acquisition of a demonstrated nuclear weapons capability by a major power. The hypothesis is that the amount of military conflict experienced by a major power will change after it acquires nuclear weapons. Note that, for the United States, this hypothesis has already been tested (due to the fact that World War II ended and the U.S. demonstrated its nuclear capability in the same year). But we can now test to see if China experienced a change in its conflict behavior after it acquired nuclear weapons.

\section{Time-Based Trends in Conflict: Correlation}

While the t-test is the most straightforward way to test changes in the amount of conflict in the post-experimental variable intervention period (either World War II or the acquisition of a nuclear weapons capability by a major power), it has at least one major vulnerability. Suppose the amount of conflict varies systematically over time (up or down, it does not matter). By splitting the observation into two time-based groups, we may conclude that the post-World War II era represents a break with the past, when it is only the final observation period of a continuous change. That is, it is not a break with the past but merely the tail end of an upward or downward trend. To guard against this possibility, the conflict measures were correlated with time. Two other variables that co-vary with time were mentioned in the discussion of why we should expect a change in conflict: the number of nations in the system and the number of nation states with a demonstrated nuclear capability. Since they offer more specific (although complementary) hypotheses than time per se, they were also correlated with the conflict measures.

\footnotetext{
'The use of 1946 as the breakpoint means, strictly speaking, that there is a single year between the acquisition of nuclear weapons by the United States and the year following the end of World War II. I do not report the U.S. analyses at the individual-individual level with this one year included in the post- period, since it contained no disputes or wars and made no difference in any results.
} 
With the aggregate-aggregate variable set, year was correlated with all measures of conflict. For each of the three types of conflict participant (major-major, major-minor, and the combination of the two), the appropriate number of dyads per year was also correlated with the conflict measures. Finally, the total number of major powers with demonstrated nuclear capability was also correlated with the conflict measures.

For the aggregate-individual variable set, much the same procedure was followed. Year was correlated with each individual major power's conflict measures, as was the total number of nuclear major powers. In place of the number of dyads, the number of nation states in the system was used to establish whether a major power's conflict experience was related to changes in the size of the global system. There were no unique individual-individual correlations; all the possibilities were covered in the aggregate-individual correlations. ${ }^{8}$

\section{Forecasting the Amount of Conflict: Probability Modeling}

The third technique of analysis involved the "forecasting" of conflict levels in the post-experimental variable era (either post-World War II or post-nuclear weapons acquisition) from the prior level of conflict to the preexperimental era. In most cases, it was also possible to measure statistically the fit of the forecasts to the observed amounts of conflict. Two different probability models were used for these forecasts. Disputes per year and wars per year were forecast using the model for the Poisson distribution, and the number of escalations from dispute to war was forecast using the model for the binomial distribution.

Given A, the average number of events occurring in a time period, the Poisson model was used to generate the probability of observing k events per unit time, $\mathrm{k}$ ranging from 0 to $\mathrm{n}$, with $\mathrm{n}$ producing a cumulative probability of .999 or greater. More specifically, in the case of forecasting disputes per year in the post-World War II era, the estimate of A was the pre-World War II average number of disputes per year. Given this figure, the probability of observing a year with 0 disputes, with 1 dispute, with 2 disputes, etc., was calculated, until the sum of these probabilities reached or exceeded .999. Multiplying each probability by the number of years in the post-World War II period produced the number of years in that period we expect to observe 0 disputes, the number of years we expect to observe 1 dispute, etc. This expected distribution, derived from the pre-World War II conflict level, was then compared with the corresponding observed distribution, and a Chi-

${ }^{8} \mathrm{~A}$ number of more sophisticated analyses could be suggested. The reader should rest assured that the more obvious ones were run and did not produce results different from those to be reported here. In particular, rank order correlations were run to check of conflict was related monotonically (but not linearly) to the predictor variables in the study, multiple regression was used to simultaneously determine the effects of the experimental intervention variables (the post-World War II and/or post-nuclear weapons acquisition variables), and the continuous control variables (time and the other time-related variables). Finally, Box-Jenkins time series analysis (ARIMA) was applied to determine if the use of correlation and regression obscured a more complicated time relationship in the conflict measures. 
square test was run to determine the probability of the observed distribution occurring, given the expected distribution. ${ }^{9}$

Given the probability, $p$, that a dispute will end in war, and given $d$ disputes, the model for the binomial distribution was used to calculate the probability of observing $w$ wars ( i.e., the number of escalations from dispute to war). The estimate for the probability, $\mathrm{p}$, was taken from the preexperimental period, and the value for $\mathrm{d}$ was the actual number of disputes observed in the post-experimental period. Unfortunately, although the probabilities of observing from 0 to $\mathrm{d}$ wars could be generated, there is only a single observed point-the actual number of escalations from dispute to war. Therefore, there is no actual "distribution" to be compared with the expected, and there is no way to compute a measure of fit corresponding to the Chi-square for the Poisson model test outlined above. ${ }^{10}$

For the aggregate-aggregate variable set, the Poisson model was used to calculate the expected distribution of disputes per year and wars per year in the post-World War II era, given the pre-World War II average. This was done separately for all three classes of dispute and war participation. The binomial was used to calculate the chances of observing the actual number of escalations to war from dispute in the post-World War II era, given the preWorld War II chances. These calculations were also done separately for each class of participant. For the aggregate-individual variable set, the two probability models were used to forecast the distribution of post-World War II disputes, wars, and the number of escalations to war, for each individual major power, given its own pre-World War II experiences. Finally, for the individual-individual variable set, the predictions were done for each individual major power, but the pre- post- breakpoint is the year of that major power's acquisition of a nuclear weapons capability.

These three types of analysis certainly do not exhaust the available techniques for detecting change, nor do the indicators used represent the entire range of measurement of levels of conflict possible from the raw data. Taken together, however, they represent a reasonable first step in evaluating whether the amount of conflict involving major powers had changed in the recent era. The discussion of results begins with the aggregate-aggregate variable set and proceeds through the aggregate-individual set to the individual-individual variable set.

${ }^{9}$ Using the model for the Poisson distribution, the probability of observing $k$ disputes in a year, $p(k)$, given, $\mathrm{A}$, the average number of disputes occurring in the pre-World War II era is:

$$
\mathrm{p}(\mathrm{k})=\frac{\mathrm{e}^{-\mathrm{A}_{\mathrm{A}} \mathrm{k}}}{\mathrm{k} !}
$$

(Derman, Gleser, and Olkin, 1973: 265-74)

${ }^{10}$ Using the model for the binomial distribution, the probability of observing $w$ wars, $p(w)$, in d disputes, given a probability, $\mathrm{p}$, of escalation from dispute to war is:

$$
p(w)=\frac{d !}{w !(d-w) !} p^{w}(1-p)^{d-w}
$$

(Derman, Gleser, and Olkin, 1973: 247-56) 


\section{Aggregate-Aggregate Results}

Table 2 displays the results of the t-tests and the correlations for the aggregate-aggregate analysis. Examining the t-tests first, we see that the number of major power interstate disputes rose sharply in the post-World War II era; the average number of disputes per year rises from 1.28 to $1.84 .{ }^{11}$ But when the number of major power interstate dyads was controlled for, the pre- post- difference was quite small. The other clear change was the sharp rise in the number of major power-major power disputes in the post-

TABle 2. Aggregate-Aggregate Major Power Analysis, 1816 - 1976

T-values: Amounts of Aggregate Conflict Per Year, Breakpoint: 1946

\begin{tabular}{lcccccc}
\hline \hline $\begin{array}{l}\text { Type of } \\
\text { Involvement }\end{array}$ & Disputes & $\begin{array}{c}\text { Disputes/ } \\
\text { Dyad }\end{array}$ & Wars & $\begin{array}{c}\text { Wars/ } \\
\text { Dyad }\end{array}$ & $\begin{array}{c}\text { Wars/ } \\
\text { Disputes }\end{array}$ & \\
\hline Major Power Interstate & $1.91^{*}$ & -.96 & -.73 & $-1.28^{* *}$ & -.74 & $(109)$ \\
Major-Major & 1.25 & $3.53^{*}$ & $-1.29^{* *}$ & $-1.26^{* *}$ & $-1.58^{* *}$ & $(51)$ \\
Major-Minor & 1.63 & $-1.76^{* *}$ & -.10 & -1.01 & -.05 & $(89)$ \\
\hline
\end{tabular}

NOTE: $\mathrm{N}=161$, except for Wars/Disputes (shown in parentheses).

Correlations: Amounts of Aggregate Conflict Per Year With Time and Time Related Measures

\begin{tabular}{|c|c|c|c|c|c|}
\hline & Disputes & $\begin{array}{l}\text { Disputes/ } \\
\text { Dyad }\end{array}$ & Wars & $\begin{array}{l}\text { Wars/ } \\
\text { Dyad }\end{array}$ & $\begin{array}{c}\text { Wars/ } \\
\text { Disputes }\end{array}$ \\
\hline \multicolumn{6}{|l|}{ Major Power Interstate } \\
\hline Year & $.24^{*}$ & $-.22 *$ & -.07 & -.21 & $-.19^{*}$ \\
\hline Number of Nations & $.32^{*}$ & $-.17^{*}$ & .00 & -.15 & -.18 \\
\hline $\begin{array}{l}\text { Number of Nuclear } \\
\text { Weapons States }\end{array}$ & $.20^{*}$ & -.08 & -.06 & -.10 & -.07 \\
\hline \multicolumn{6}{|l|}{ Major-Major } \\
\hline Year & $.17^{*}$ & $.18^{*}$ & -.03 & $-.19^{*}$ & -.19 \\
\hline Number of Nations & $.15^{*}$ & $-.12^{*}$ & .13 & -.08 & .07 \\
\hline $\begin{array}{l}\text { Number of Nuclear } \\
\text { Weapons States }\end{array}$ & .08 & $.20^{*}$ & -.09 & -.08 & -.20 \\
\hline \multicolumn{6}{|l|}{ Major-Minor } \\
\hline Year & $.20^{*}$ & $-.19^{*}$ & -.08 & -.19 & -.14 \\
\hline Number of Nations & $.28^{*}$ & -.14 & -.03 & -.15 & -.12 \\
\hline $\begin{array}{l}\text { Number of Nuclear } \\
\text { Weapons States }\end{array}$ & $.13^{*}$ & -.11 & -.01 & -.08 & -.05 \\
\hline
\end{tabular}

*Significant at the .05 level

**Significant at the .05 level if degrees of freedom are modified for unequal pre- and post- variances

\footnotetext{
${ }^{11}$ Tables containing descriptive statistics and the probability model results are available from the author: reference will be made to figures from these tables when appropriate.
} 
World War II era when the number of major-major dyads was controlled for (from .024 per year to .063 per year).

For some of the other variables indicated in the table, if a correction for unequal variances in the pre- and post- eras was made, the t-tests indicate a significant shift in levels of conflict. However, since the post- group has 31 observations, it is not clear that such an adjustment was really necessary. Note that all of the effected t-tests (predominantly for major-major participation) indicate a downward shift in conflict levels in the post-World War II era. Concentrating on the signs of the t-tests, a general trend emerges: the number of disputes per year rises is all categories, but the number of wars shows no corresponding rise; in fact, some decline is discernible.

The correlations are, without exception, modest. The largest is .32, accounting for only about 10 percent of the variance in the dependent variable. I hesitate to dwell on them, but a few summary comments are in order. First (and most obvious), there is no evidence of a strong linear trend over time. Second, the highest associations are usually with year and the lowest with the number of majors possessing nuclear weapons. Third, with the exception of disputes per year, the associations with time and the other time-related variables are negative. Overall, then, there is a very modest downward linear trend over the time period, and this is most closely associated with time itself, and not the two time-related variables of number of dyads, and number of majors possessing nuclear weapons.

Table 3 displays a summary of the results of probability model forecasts. Turning first to the major power-interstate results, the number of disputes in the post-World War II era is significantly different from the pre-World War II level; many more occur than would be expected. A difference also occurs in the number of wars (less occur after World War II than would be expected), but it is not statistically significant. With regard to escalation from dispute to war, fewer than expected escalations occur (four are observed; nine were expected from the pre-World War II frequency). Not surprisingly, the chances of observing only four escalations out of the fifty-nine post-World War II major power-interstate disputes was quite slight (.03), given the .14 probability of escalation in the earlier era.

Table 3. Probability Model Results: System Level Pre- Post-World War II Breakpoint

\begin{tabular}{|c|c|c|c|c|c|c|c|}
\hline \multirow{3}{*}{$\begin{array}{l}\text { Nation State } \\
\text { Involvement }\end{array}$} & \multicolumn{7}{|c|}{ Measure of Conflict } \\
\hline & \multicolumn{3}{|c|}{ Disputes Per Year } & \multicolumn{3}{|c|}{ Wars Per Year } & \multirow{2}{*}{$\begin{array}{c}\text { Wars Per Dispute } \\
\operatorname{Pr}(\text { Observed Wars })\end{array}$} \\
\hline & $\chi^{2}$ & $d f$ & Prob. & $\chi^{2}$ & $d f$ & Prob. & \\
\hline $\begin{array}{l}\text { Major Power } \\
\text { Interstate }\end{array}$ & 21.57 & 5 & $<.001(\mathrm{H})$ & .79 & 2 & $.60(\mathrm{~L})$ & .03 \\
\hline $\begin{array}{l}\text { Major Power- } \\
\text { Major Power }\end{array}$ & 4.99 & 3 & $.15(\mathrm{H})$ & 2.00 & 1 & $.15(\mathrm{~L})$ & .04 \\
\hline $\begin{array}{l}\text { Major Power- } \\
\text { Minor Power }\end{array}$ & 22.21 & 4 & $<.001(\mathrm{H})$ & .31 & 1 & $.60(\mathrm{H})$ & .13 \\
\hline
\end{tabular}

Note: $\mathrm{H}$ or $\mathrm{L}$ after Chi-Square Probability indicates whether post-breakpoint amount of conflict is higher or lower than pre-breakpoint amount. 
When major-major conflict experience is separated out, the results are much the same. However, the distribution of disputes that actually occurred fit the expected better than was the case for all major power-interstate disputes, and the number of wars does not fit as well. The chances of observing the actual number of escalations to war (o) is, of course, quite small.

The major-minor results display some differences from the previous findings. The observed distribution of disputes is higher than the expected, but the observed number of wars is close to the expected number. Not surprisingly, the number of actual escalations was closer to the expected number than for the major power interstate or major-major disputes.

Summarizing the aggregate-aggregate findings, the absolute number of disputes is higher in the post-World War II era; but as might be expected, a considerable deflation occurs when the number of possible nation-dyads is controlled for. The exception to this decline is major-major disputes, which show a rise when the number of major power dyads is controlled for; as noted before, there are fewer major powers in the post-World War II era than in the previous 130 years.

On the brighter side, although the number of disputes has risen, the number of wars has not, even without controlling for the larger system size. In fact, there is some evidence of a modest decline in the number of wars and in the escalation from dispute to war.

\section{AgGregate-Individual Analyses}

In this second set of analyses, the predictor variables remain the same, but the outcome variables now represent the conflict experiences of each individual major power. This is done to guard against the ecological fallacy; there is no guarantee that any change in aggregate major power-interstate behavior is mirrored in the experiences of each and every individual major power, as well as for intrinsic interest in the different experiences of the individual major powers (see above).

Table 4 displays the results of the t-tests and correlations for each major power's conflict experience. China is excluded from these analyses since it was not a major power both before and after World War II (thus providing no "pre" group). Recall also that, because of the small number of events (disputes and wars) for each major power, the conflict experiences were not broken down into the three classes of participation that were used in the aggregate-aggregate analyses.

The findings are not earthshaking, but, once again, some overall patterns emerge. Signs of increased involvement in disputes per year are present for both the United States (dramatically) and the Soviet Union (less so). This increased involvement in disputes (contrasted with no change or a drop-off for Britain and France) was not unexpected. As noted above, the two superpowers were (and are) the leaders of blocs of rival countries and engaged in many global confrontations during this period. When the conflict measure is disputes per nation, however, the increases in superpower involvement disappear; in fact, the Soviet Union shows a drop, although it is not statistically significant. Drops for Britain and France are even more pronounced. With 
Table 4. Aggregate-Individual Major Power Analysis, 1816 - 1976

T-Values: Amounts of Individual Conflict Per Year, Breakpoint: 1946

\begin{tabular}{|c|c|c|c|c|c|c|}
\hline Nation & $(N)$ & Disputes & $\begin{array}{l}\text { Disputes/ } \\
\text { Nations }\end{array}$ & Wars & $\begin{array}{c}\text { Wars/ } \\
\text { Nations }\end{array}$ & $\begin{array}{c}\text { Wars/ } \\
\text { Disputes }\end{array}$ \\
\hline United States & (78) & $2.57^{*}$ & .06 & .35 & .31 & $.66(30)$ \\
\hline United Kingdom & $(161)$ & .16 & $-2.13^{*}$ & .36 & .40 & $.28(77)$ \\
\hline France & (155) & -1.26 & $-2.74^{*}$ & .30 & -.99 & $-.17(55)$ \\
\hline USSR & $(157)$ & 1.62 & -1.23 & -1.29 & -1.26 & $-1.97(54)$ \\
\hline
\end{tabular}

Note: Total $\mathrm{N}$ given in second column. $\mathrm{N}$ for Wars/Disputes in parentheses after last column Correlations: Amounts of Individual Conflict With Time and Time Related Measures

\begin{tabular}{|c|c|c|c|c|c|}
\hline & Disputes & $\begin{array}{l}\text { Disputes/ } \\
\text { Nations }\end{array}$ & Wars & $\begin{array}{c}\text { Wars/ } \\
\text { Nations }\end{array}$ & $\begin{array}{l}\text { Wars/ } \\
\text { Disputes }\end{array}$ \\
\hline \multicolumn{6}{|l|}{ Year } \\
\hline United States & .20 & -.14 & .01 & -.07 & -.11 \\
\hline United Kingdom & .00 & $-.20^{*}$ & .02 & -.06 & .01 \\
\hline France & -.05 & -.22 & -.05 & -.14 & -.12 \\
\hline USSR & .16 & -.09 & -.03 & -.09 & -.18 \\
\hline \multicolumn{6}{|l|}{ Number of Nations } \\
\hline United States & .29 & -.06 & -.01 & -.08 & -.19 \\
\hline United Kingdom & -.02 & $-.21^{*}$ & -.01 & -.05 & -.03 \\
\hline France & -.09 & -.24 & -.07 & -.12 & -.11 \\
\hline USSR & .15 & -.13 & -.03 & -.06 & -.23 \\
\hline \multicolumn{6}{|l|}{$\begin{array}{l}\text { Number of Nuclear Weapons } \\
\text { States }\end{array}$} \\
\hline United States & $.34^{*}$ & .02 & .03 & -.05 & -.18 \\
\hline United Kingdom & -.02 & $-.18^{*}$ & -.01 & -.05 & -.04 \\
\hline France & -.11 & $-.21^{*}$ & -.06 & -.09 & -.05 \\
\hline USSR & .12 & -.11 & -.10 & -.09 & -.24 \\
\hline
\end{tabular}

*Significant at the .05 level

regard to the war and escalation measures, no nation shows an increase; the Soviet Union's war and escalation measures are close to being statistically significant in a downward direction.

For Britain and France there is a drop in dispute involvement when the number of nation states in the system is controlled for, but little change in their conflict involvement is evident elsewhere in the table. That their involvement in disputes has, by one measure, dropped off is not surprising, considering that their roles in the international system (and their capabilities to intervene globally) have changed. Perhaps more interesting is that a drop in conflict involvement is not more prevalent.

A few words should be said specifically about the correlations. Once again, the values are small. The largest, .34, only accounts for 12 percent of 
the variance in the dependent variable. If one is willing to accept correlations of .20 or greater as indicative of a modest relationship, we can draw a few inferences. For both Britain and France, dispute per nation involvement has shown a slight decline over time. It appears that the post-World War II drop on this measure indicated by the t-tests is, in part, the culmination of a longterm downward trend.

For the United States, there is also evidence of a modest trend over time in dispute involvement-in an upward direction. The strongest of the correlations is with number of major powers with nuclear weapons, and the next strongest correlation is with the number of nations. Both these measures rise quite steeply after World War II. This indicates that the rise in U.S. involvement is greatest in the post-World War II era, and this finding corresponds to both our expectations and the results of the t-tests.

The summary of the probability models for the aggregate-individual analysis is displayed in Table 5. For dispute involvement there are no surprises; the United States and the Soviet Union have more involvements than their pre-World War II levels would lead us to expect (although the Chi-square for the Soviet Union falls just short of the .05 significance level), while Britain and France show little deviation from their expected levels. With regard to number of wars, no major power's involvement is significantly different from its pre-World War II involvement.

TABle 5. Probability Model. Results:

Individual MAjor POWERs Pre- POST-WORLd WAR II BREAKPOINT

\begin{tabular}{lccccccc}
\hline \hline & \multicolumn{7}{c}{ Measure of Conflict } \\
\cline { 2 - 8 } Major Powers & $\chi^{2}$ & $d f$ & Prob. & $\chi^{2}$ & $d f$ & Prob. & Pr (Observed Wars) \\
\hline United States & 96.60 & 3 & $<.001(\mathrm{H})$ & .41 & 1 & $.60(\mathrm{H})$ & .13 \\
United Kingdom & 1.35 & 4 & $.85(\mathrm{H})$ & .31 & 1 & $.85(\mathrm{H})$ & .28 \\
France & 2.19 & 4 & $.75(\mathrm{~L})$ & .13 & 2 & $.93(\mathrm{~L})$ & .29 \\
Soviet Union & 7.04 & 3 & $.07(\mathrm{H})$ & 1.35 & 2 & $.60(\mathrm{~L})$ & .05 \\
& & & & .36 & 2 & $.80(\mathrm{~L})$ & .13 \\
\hline \hline
\end{tabular}

NOTE: $\mathrm{H}$ or $\mathrm{L}$ after Chi-Square probability indicates whether post-breakpoint amount of conflict is higher or lower than pre-breakpoint amount. Second set of figures for the Soviet Union includes a war coded as the outcome of the 1968 Czech dispute.

It is in the prediction of escalation from dispute to war that the most interesting findings emerge. As might be anticipated, the probability of observing the number of escalations by the United States and the Soviet Union is quite low; both would be most likely to have been involved in four wars and were actually involved in two and one (or two, with Czechoslovakia), respectively. The surprise comes when we examine the predictions for Britain and France. Given the number if dispute involvements for each, the most likely number of war involvements is one. Both are actually involved in two interstate wars (Korea in 1950 and the Sinai War in 1956). 
The separate analyses of each major power's post-World War II conflict involvement have produced some interesting findings. Dispute involvement for the two superpowers is up in this era, although this increase disappears when the number of nations in the system is taken into account. Dispute involvement for Britain and France has not risen in this era, and when the number of nations in the system is taken into account, it has fallen. War involvement for all majors has not risen. The combination of these two effects means that the chances of escalation for the United States and the Soviet Union are lower in the current era than in the past, while the correspondering changes of escalation are a bit higher for Britain and France. This later finding is due to the fact that, while the number of British and French war involvements has not risen, their dispute involvement has fallen. While it is discouraging that the dispute involvement of the two superpowers has not fallen, at least we can take solace from the fact that their escalation propensities have decreased. On the other hand, for the non-superpower major powers, although dispute involvement is down, there is no decrease in the chance of escalation to war.

\section{INDIVIDUAL-INDIVIDUAL ANALYSES}

The final set of analyses shifts the breakpoint for each major power's conflict experience to the date that each demonstrated a capacity to build nuclear weapons. Note that, because of the coincidence of the end of World War II and the dropping of the first atomic bombs, the individual-individual analysis for the United States is identical to the aggregate-individual analyses just reported, and it will not be repeated. The correlations with time and time-related variables that were shown in Table 4 are also identical to the individual-individual correlations for the four major powers discussed above, so these too will not be repeated. An additional nation is added to the analyses: China, which becomes a major power in 1950. The correlations for China are reported in Table 6.

For the major powers that were also included in the aggregate-individual analyses, there are few changes when the breakpoint is shifted. As before, only a small number of the t-tests are statistically significant; both Britain and France show drops in disputes per nation in the post-break period (as in the previous analyses), and the pattern for the Soviet Union is identical to that obtained in the aggregate-individual analyses. About the only change occurs in French dispute involvements. In the earlier analyses, their involvement declined in the post-World War II period, while it increases when the date of their acquisition of a nuclear weapons capability is used. Note, however, that neither t-test is statistically significant. More will be said about this later.

China experiences no change in dispute involvement after the acquisition of nuclear weapons, and all of the other conflict indicators show small to moderate drops over time. However, China is only a major power for a small number of years, and dividing its conflict experiences into two groups leaves few cases in both groups. The drop over time in Chinese escalation to war (as evidenced by the t-tests and especially the correlations) is particularly interesting - but note that this variable only has eleven time points. 
TABLE 6. Individual-Individual Major Power Analysis, 1816 - 1976

T-VALUe: Amounts of Individual Conflict Per Year, Breakpoint: Acquisition of Nuclear Weapons

\begin{tabular}{llcccrr}
\hline \hline Nation & Disputes & $\begin{array}{l}\text { Disputes/ } \\
\text { Nations }\end{array}$ & Wars & $\begin{array}{c}\text { Wars/ } \\
\text { Nations }\end{array}$ & $\begin{array}{c}\text { Wars/ } \\
\text { Disputes }\end{array}$ \\
\hline United States & & & \multicolumn{2}{c}{ Results identical to those in Table 4} \\
United Kingdom & $(25)^{* *}$ & .12 & $-2.00^{*}$ & -.24 & -.67 & $.02(67)$ \\
France & $(17)$ & 1.07 & $-2.13^{*}$ & $-1.27^{\prime}$ & $-1.19^{\prime}$ & $-.98^{\prime}(55)$ \\
USSR & $(28)$ & 1.20 & $-1.49^{\prime}$ & $-1.20^{\prime}$ & $-1.18^{\prime}$ & $-1.73^{\prime}(54)$ \\
China & $(13)$ & .14 & -.59 & -1.41 & -1.38 & $-1.32(11)$ \\
\hline
\end{tabular}

NOTE: Total $\mathrm{N}$ given in second column. $\mathrm{N}$ for Wars/Disputes in parentheses after last column.

Correlations: Amounts of Individual Conflict With Time and Time Related Measures

\begin{tabular}{lccccc}
\hline \hline Nation & Disputes & $\begin{array}{c}\text { Disputes/ } \\
\text { Nations }\end{array}$ & Wars & $\begin{array}{c}\text { Wars/ } \\
\text { Nations }\end{array}$ & $\begin{array}{c}\text { Wars/ } \\
\text { Disputes }\end{array}$ \\
\hline China & & & & & \\
Year & .05 & -.11 & -.25 & -.29 & -.48 \\
Number of Nations & .03 & -.14 & -.18 & -.23 & -.36 \\
$\begin{array}{l}\text { Number of Nuclear Weapons } \\
\quad \text { States }\end{array}$ & .02 & -.15 & -.28 & -.33 & -.51 \\
\hline
\end{tabular}

'Significant at the .05 level if degrees of freedom are modified for unequal pre- and post- variances

*Significant at the .05 level

** Number of post-nuclear weapons years; total $\mathrm{N}$ for each nation are the same as in Table 4, except for China, which is 27 .

Turning to the summary of the probability models (Table 7), all major powers show no significant differences from anticipated behavior in dispute predictions. But the fit is generally better for Britain and France than for China and the Soviet Union.

The wars per year for each major power hold few surprises. With the exception of Britain, each major power experiences slightly less war than predicted. Britain's war involvement is as expected, given their previous experience. Regarding the number of escalations to war, given the number of dispute involvement, as with the aggregate-individual analyses, Britain and France display little change from their pre-nuclear periods. Both the Soviet Union and China experienced less escalation than expected from their prenuclear experience.

The patterns in the individual-individual analyses are similar to those in the aggregate-individual analyses. Few dramatic shifts in behavior are evident in the "post" eras. Britain and France's dispute per nation involvement is less in their post-nuclear period, but their number of escalations to war is close to that of the pre-nuclear era. Soviet dispute involvement is up when disputes per year is used and down when the system size is taken into account. China shows little change on either dispute measure. Using any of the measures of war involvement, both of these superpowers are involved in 
TABle 7. Probability Model Results:

Individual, Major Powers Pre-Post Nuclear Weapons Breakpoint

\begin{tabular}{|c|c|c|c|c|c|c|c|}
\hline \multirow[b]{3}{*}{ Major Power } & \multicolumn{7}{|c|}{ Measure of Conflict } \\
\hline & \multicolumn{3}{|c|}{ Disputes Per Year } & \multicolumn{3}{|c|}{ Wars Per Year } & \multirow{2}{*}{$\begin{array}{c}\text { Wars Per Dispute } \\
\text { Pr(Observed Wars) }\end{array}$} \\
\hline & $\chi^{2}$ & $d f$ & Prob. & $\chi^{2}$ & $d f$ & Prob. & \\
\hline \multicolumn{8}{|c|}{ United Kingdom } \\
\hline $1952-1976$ & .82 & 4 & $.93(\mathrm{H})$ & .02 & 1 & $.85(\mathrm{~L})$ & .37 \\
\hline \multicolumn{8}{|l|}{ France } \\
\hline $1960-1976$ & 1.87 & 3 & $.75(\mathrm{~L})$ & 1.56 & 2 & $.40(\mathrm{~L})$ & .38 \\
\hline \multicolumn{8}{|c|}{ Soviet Union } \\
\hline \multirow[t]{2}{*}{$1949-1976$} & 4.32 & 3 & $.25(\mathrm{H})$ & 1.02 & 2 & $.60(\mathrm{~L})$ & .12 \\
\hline & & & & .19 & 2 & $.93(\mathrm{~L})$ & .20 \\
\hline \multicolumn{8}{|l|}{ China } \\
\hline $1964-1976$ & 4.18 & 4 & $.40(\mathrm{~L})$ & 2.00 & 2 & $.40(\mathrm{~L})$ & .10 \\
\hline
\end{tabular}

NOTE: $\mathrm{H}$ or $\mathrm{L}$ after Chi-Square probability indicates whether post-breakpoint amount of conflict is higher or lower than pre-breakpoint amount. Second set of figures for the Soviet Union includes a war coded as the outcome of the 1968 Czech disputes. Years below each nation indicate the post-nuclear weapons period.

fewer wars. In sum, there is little evidence of a dramatic and constant effect on conflict behavior from the possession of nuclear weapons. Any changes that did occur in conflict involvement appear to have been underway by the end of World War II.

\section{CONCLUSION}

This paper began by enumerating a number of reasons why the postWorld War II era might be expected to have marked a change in the level of interstate conflict. Despite general agreement on the major changes in this era, there is much less consensus about the effect of each of these changes on the level of conflict. It is this conceptual disarray that accounts for the inductive character of this research; there was just too little agreement in the literature to allow for a more deductive investigation. As such, the conclusions that can be drawn from the results are less focused than one might wish.

At the system level the number of disputes per year has increased over time, but when the number of nations in the system is used to deflate the frequency, there is no rise except for major power-major power disputes. Thus, major power involvement in disputes has increased only at the rate expected, given the rise in independent nation states. Since the creation of new nation states in the international system has about ceased, the absolute number of disputes per year can be expected to level off in the near future. This one exception to this is the rise in direct (major power-major power) disputes. This rise is undoubtedly due to the antagonism of the Cold War. The United States (to a great extent) and the Soviet Union (to a lesser extent) show increases in disputes, while the United Kingdom and France do not. Thus, the individual major power analyses shed additional light on the findings of the system level. The particularly dramatic increase in dispute 
involvement by the United States is indicative of its rise to superpower status from non-involvement in global affairs. The less dramatic Soviet increase perhaps reflects its shorter step from active major power to superpower rival.

The finding concerning Britain and France's dispute involvement are, for the most part, consistent with their decrease in status in the post-World War II era. When the measure of conflict is dispute per nation per year, both experience a drop in involvement. However, when disputes per year is used, one disquieting discovery was made. Using the 1946 breakpoint, the United Kingdom shows no change in dispute involvement, and this finding is repeated when the nuclear weapons breakpoint is substituted. France, however, is a different matter. Disputes per year shows a drop when 1946 is used but a rise when the nuclear weapons breakpoint is used. As mentioned earlier, neither of these values is statistically significant, but the shift in sign is worth pondering. France is the only nation in the study that (a) was a major power before and after World War II and (b) developed nuclear weapons a number of years after the war. The joint impact of the two findings is to argue that the immediate impact of the World War II experience on France was to decrease its involvement in interstate disputes. But the development of nuclear weapons co-varied with an increase in French disputes per year. The results are not strong, and any causality is far from established, but there is a hint of a nuclear weapons effect. Note that, when the number of nation states is used as a denominator, France shows a significant drop in disputes per year.

War involvement by the major powers, collectively and individually, shows no increase. When the number of nations in the system is controlled for, there is even evidence of a decrease (as there is for major-minor war). The combined effect of both the previous sets of findings is that the changes of escalation from dispute to war are no greater, and may well be less, in the post-World War II era. This time period provides ample opportunity for major power conflict but has seen a reluctance of these governments to take the final step to war. We should not rest easily, though, since the potential cost of any war involving a major power is far greater now than ever before. Looking forward, the immediate threat of a renewed active rivalry between the United States and the Soviet Union is an increase in disputes but not necessarily an increase in chances of war.

The effect of controlling for number of nations on dispute and war noted in this paper has implications for the system structure debate mentioned at the beginning of the paper. The focus on system structure and conflict has perhaps underplayed (although not ignored) the effect of system size. More attention should be devoted to the separate and interactive effects of both variables on conflict.

A final word about proliferation is necessary. Three of the nations in this study proliferated shortly after World War II. This action appears to have no unique effect on their conflict involvement beyond a general post-World War II effect. However, there may not be enough of a gap between these breakpoints to discriminate between the two. The French case is the only nation that might allow this, and the results are disturbing, albeit not dramatic. 
A further question can be raised about the applicability of these results to minor powers. This is particularly crucial with regard to proliferation. Are the hints from the French results a harbinger of the future? Only time will tell, but the problem merits close attention, particularly since the findings of this paper are ambiguous on this point.

Returning to the major powers, it would seem, then, that high levels of power in the post-World War II era go hand-in-hand with high levels of dispute involvement but not high levels of war involvement. For this we can be grateful. Despite this, however, and despite the lack of a demonstrated nuclear weapons effect for the superpowers, we must remember that the costs of a possible major power war have climbed to unprecedented levels with the introduction of these weapons. If we are to have a good chance of surviving to the year 2000 , we must be wary that any use of military force by a major power could lead to a disaster for all of mankind.

\section{REFERENCES}

Art, Robert (1980). “To What Ends Military Power?’' International Security 4 (Spring 1980): 3-35.

Bueno de Mesquita, Bruce (1975). “Measuring Systemic Polarity." Journal of Conflict Resolution 19 (June 1975): 187-216.

Campbell, Donald and Julian Stanley (1963). Experimental and Quasi-Experimental Designs for Research. Chicago: Rand McNally.

Cusack, Thomas (1978). The Major Powers and the Pursuit of Security in the Nineteenth and Twentieth Centuries. Ann Arbor: University of Michigan Doctoral Dissertation.

Derman, Cyrus, Leon Gleser, and Ingram Olkin (1973). A Guide to Probability Theory and Application. New York: Holt, Rinehart, and Winston.

$\rightarrow$ Deutsch, Karl and J. David Singer (1964). "Multipolar Power Systems and International Stability.' World Politics 16 (April 1964): 390-406.

Gochman, Charles (forthcoming). The Disputes of the Major Powers, 1816-1975.

Gray, Colin and Keith Payne (1980). "Victory is Possible." Foreign Policy 39 (Summer 1980): 14-27.

$\rightarrow$ Halle, Louis (1973). “'Does War Have a Future?’' Foreign Affairs 52 (Fall 1973): 20-34.

Kegley, Charles, Gregory Raymond, and Kyungsook Lee Choi (1979). “Fluctuations in Legal Norms and Arbitral Behavior, 1825-1970.' Paper prepared for delivery at the International Political Science Association Congress, Moscow, August 1979.

Keohane, Robert and Joseph Nye (1977). Power and Interdependence. Boston: Little, Brown.

Rosecrance, Richard (1966). "Bipolarity, Multipolarity, and the Future." Journal of Conflict Resolution 10 (September 1966): 314-327.

Singer, J. David and Melvin Small (1972). The Wages of War. New York: Wiley.

1979. "Conflict in the International System, 1816-1977: Trends and Policy Futures." In Charles Kegley and Patrick McGowan, eds., Challenges to America. Beverly Hills: Sage, 89-116.

Waltz, Kenneth (1967). "International Structure, National Force, and the Balance of World Power." Journal of International Affairs 21 (June 1967): 215-31. 